\title{
Analisis Penilaian Kinerja Dengan Menggunakan Metode Balanced Scorecard Di Rumah Sakit Dr.Etty Asharto Batu
}

\author{
Maratus Sholihah Aprilia Kosasih1, ${ }^{\text {, Suprapti² }}$ \\ 1 Universitas Merdeka Malang,Jalan Terusan Raya Dieng 62-64,Malang,65138,Indonesia \\ 2 Universitas Merdeka Malang,Jalan Terusan Raya Dieng 62-64,Malang,65138,Indonesia
}

Keywords:

SMES; application of accounting

Kata Kunci

Penilaian Kinerja, Balanced Scorecard, Rumah

Sakit dr.Etty Asharto Batu
ABSTRACT

This research purposely made to evaluate the performance of Balanced Scorecard method on dr. Etty Asharto Hospital in Batu. There are two aspects evaluated, finance and non finance aspect, using perspectives of the customers'; internal business process'; educational and developments'; and finance's as in the Balanced Scorecard perspective. The research's information was taken from the finance data collection from 2014 to 2018. This research using descriptive analysis by giving score based on the criteria on the 4 Perspectives of Balanced Scorecard and then analyzed to determine whether the score is good, enough, or bad. The instruments of the research are interview, questionnaire, and literature review as the primer and secondary variety. The sample was taken from 152 customers and the staff of dr. Etty Asharto Hospital in Batu. Based on the result of the research, it can be concluded that the performance of dr. Etty Asharto in Batu was scored to be enough, The performance scoring using Balanced Scorecard method in $d r$. Etty Asharto Hospital could be enforced in the future because the method could provide more structured also could widely relate and present the 4 Perspective of Balanced Scorecard better.

\footnotetext{
ABSTRAK

Penelitian ini bertujuan untuk menilai kinerja menggunakan metode balanced scorecard di Rumah Sakit dr.Etty Asharto Batu. Aspek yang dinilai ialah aspek keuangan dan non keuangan melalui empat perspektif balanced scorecard yaitu perspektif pelanggan, perspektif proses bisnis internal, perspektif pembelajaran dan pertumbuhan, dan perspektifkeuangan. Penelitian mengambil data selama lima tahun, yaitu tahun 2014-2018. Penelitian menggunakan analisis deskriptif dimana peneliti melakukan penilaian kinerja dengan cara memberikan skor sesuai kriteria pada empat perspektif balanced scorecard kemudian di analisis untuk menentukan baik, cukup, atau kurang baik. Data diperoleh dari interview, kuisioner, dan studi pustaka dengan jenis data primer dan sekunder. Sampel yang digunakan sebanyak 152 sampel dengan pelanggan dan karyawan Rumah Sakit dr.Etty Asharto Batu. Berdasarkan hasil penelitian, dapat disimpulkan kinerja Rumah Sakit dr.Etty Asharto Batu dinyatakan cukup jika dilihat dari empat perspektif dalam balanced scorecard. Penilaian kinerja menggunakan metode balanced scorecard dapat terus digunakan untuk kedepanya dikarenakan balanced scorecard mampu memberikan gambaran lebih luas dan terstruktur dibanding dengan sistem tradisional.
} 


\section{PENDAHULUAN}

Banyak perusahaan yang masih menggunakan pendekatan tradisional untuk menilai kinerja perusahaanya. Padahal seiring perkembangan zaman, penilaian kinerja perusahaan menggunakan pendekatan tradisional dianggap kurang efektif. Hal ini dikarenakan metode penilaian kinerja menggunakan pendekatan tradisional lebih menekankan terhadap aspek keuangan. Sedangkan untuk dapat bersaing dan tetap eksis di zaman sekarang perusahaan selain membutuhkan pengukuran dengan aspek keuangan dibutuhkan pula pengukuran dengan aspek non keuangan. Pengukuran aspek non keuangan dibutuhkan untuk menunjang aspek keuangan. Aspek-aspek non keuangan sering diabaikan oleh manajemen dikarenakan sulit untuk diukur. Aspek-aspek non keuangan seperti: peningkatan kompetensi oleh karyawan, loyalitas karyawan, peningkatan dari produktivitas, serta keefektifan dan keefisienan ekonomi dapat diukur dengan metode pendekatan kontemporer. Metode penilaian kinerja kontemporer yang dapat mengukur aspek keuangan serta aspek non keuangan adalah metode penilaian kinerja balanced scorecard.

Balance scorecard pertama kali dikembangkan oleh Robert S. Kaplan dan David P. Norton. Penggunaan metode balance. scorecard akan membantu untuk mengoptimalkan pencapaian pertumbuhan dan peningkatan kinerja perusahaan.Dalam metode balanced scorecard, penilaian kinerja dapat dilihat berdasarkan pada empat aspek, yaitu aspek keuangan (financial performance), aspek kepuasan konsumen (custumer satisfaction), aspek bisnis internal (internal business proses), serta aspek pembelajaran dan pertumbuhan (learning and growth aspect).

Pada setiap yang aspek di dalam balanced scorecard dapat diketahui seberapa baik konsisi keuangan sebuah perusahaan, seberapa besar tingkat kepuasan pelanggan, seberapa baik proses untuk mengembangkan usaha peeusahaan sesuai dengan visi dan misinya, dan seberapa besar tingkat kepuasan orang-orang yang terlibat ddidalam perusahaan. Berdasarkan penilaian tersebut maka perusahaan dapat mengetahui kelebihan dan kekuranganya. Saat ini peneliti ingin meneliti mengenai penilaian kinerja menggunakan balanced scorecard pada perusahaan di bidang jasa yaitu rumah sakit.

a. Penilaian Kinerja

Penilaian kinerja merupakan cara menentukan efektivitas operasional suatu organisasi secara periodik, bagian organisasi dan personilnya berdasarkan sasaran yang strategic, standart dan kriteria yang telah ditentukan sebelumnya (Laksmita dan Januarti, 2011).

b. Balanced Scorecard

Balanced scorecard merupakan kartu skor yang digunakan untuk menilai kinerja yang memperhatikan titik seimbang antara sisi keuangan dan non keuangan, jangka pendek dan jangka panjang, serta melibatkan pihak internal serta eksternal (Darmiyati, 2013).

c. Rumah Sakit

Rumah sakit merupakan suatu bentuk organisasi yang mengelola pelayanan berupa jasa kesehatan individual secara menyeluruh. Agar dapat menjalankan fungsi rumah sakit, dibutuhkan suatu sistem manajemen men yeluruh yang diawali dari proses perencanaan strategik, baik untuk yang jangka pendek maupun untuk yang jangka panjang. Pada perencanaan strategik bisa dikatakan baik apabila perencanaan dapat ditindaklanjuti secara praktis dalam program operasional yang berlandaskan economic - quality quantity. Dengan begitu, rumah sakit harus dikelola secara efektif, efisien, serta melayani segala lapisan masyarakat dan berkualitas (Aurora, 2010)

\section{METODE}

\section{Variabel Penelitian}

Variabel yang digunakan untuk mengevaluasi kinerja pada Rumah Sakit dr. Etty Asharto adalah dengan menggunakan empat perspektif dalam metode balanced scorecard, yaitu pada perspektif keuangan, perspektif pelanggan, perspektif proses bisnis internal, dan perspektif pembelajaran dan pertumbuhan.

\section{Perspektif Keuangan}

Indikator yang digunakan untuk menilai perspektif keuangan adalah : (1) Rasio Ekonomis, (2) Rasio Efisiensi, (3) Rasio Efektivitas. 
Perspektif Pelanggan

Indikator yang digunakan untuk menilai perspektif pelanggan ialah :(1) Kepuasan Pelanggan, (2) Akuisisi Pelanggan, (3) Retensi Pelanggan.

Perspektif Proses Bisnis Internal

Indikator yang digunakan untuk menilai perspektif proses bisnis internal adalah : (1) Bed Occupancy Ratio, (2) Bed Turn Over, (3) Turn Over Interval, (4) Average Leanght of Stay, (5) Gross Death Rate, (6) Net Death Rate.

\section{Perspektif Pembelajaran dan Pertumbuhan}

Indikator yang digunakan pada perspektif pembelajaran dan pertumbuhan ialah : (1) Tingkat Kepuyasan Karyawan, (2) Perputaran Karyawan, (3) Produktivitas Karyawan.

\section{Waktu dan Lokasi Penelitian}

Waktu yang digunakan dalam penelitian adalah 5 tahun yaitu dari tahun 2014-2018 serta penelitian berlokasi di Rumah Sakit dr. Etty Asharto Batu yang terletak di Jl. Sajid No.44 Batu 65313.

\section{Teknik Analisis Data}

\section{Uji Validitas}

Pengujian dengan menggunakan uji validitas dengan cara membandingkan nilai Sig. ( 2 - tailed) dengan probabilitas 0,05. Jika nilai Sig. ( 2 - tailed) $<0,05$ dan Pearson Correlation bernilai positif, maka item pada angket dinyatakan valid. Jika nilai Sig. ( 2 - tailed) $<0,05$ dan Pearson Correlation bernilai negatif, maka item pada angket dinyatakan tidak valid. Jika nilai Sig. (2 - tailed) $>0,05$, maka item pada angket dinyatakan tidak valid.

\section{Uji Reabilitas}

Uji realibilitas dilakukan dengan cara membandingkan angka cronbach alpha dengan dekentutan nilai cronbach alpha minimal adalah 0,6 . Hal ini berarti jika nilai cronbach alpha yang didapatkan dari hasil perhitungan SPSS lebih besar dari 0,6 maka disimpulkan kuisioner tersebut reliabel, sebaliknya jika cronbach alpha lebih kecil dari 0,6 maka disimpulkan kuisioner tidak reliabel.

\section{Deskriptif Kuantitatif}

Metode deskriptif kuantitatif dapat dilakukan dengan cara sebagai berikut :

Menjelaskan data-data yang sudah didapat, seperti data mengenai keuangan rumah sakit dr. Etty Asharto Batu, laporan standar kinerja pada rumah sakit dr. Etty Asharto Batu serta data-data karyawan rumah sakit dr. Etty Asharto Batu yang kemudian diolah menjadi pemicu ukuran kinerja.

Membubuhkan skor pada masing-masing pemacu kinerja, baik pada kinerja menurut penilaian rumah sakit dr. Etty Asharto Batu maupun kinerja yang berdasarkan pada empat perspektif Balanced Scorecard. Adapun Penilaian balanced scorecard adalah sebagaimana disajikan dalam Tabel 1.

Menentukan kinerja "baik, "cukup", juga "kurang" dengan menggunakan skala penilaian kinerja Balanced Scorecard dari hasil memberikan skor terhadap masing-masing indikator. Kinerja dibilang "kurang" jika besar nilai kinerja kurang dari 50\% (skor -1). Kinerja dibilang "baik" apabila lebih dari 80\% (skor 1) dan diasumsikan bahwa $80 \%$ sama dengan skor 0,6. Sisanya merupakan daerah "cukup" apabila lebih besar sama dengan $50 \%$ dan kurang dari sama dengan $80 \%$ skor antara 0-0,6.

Tabel 1

Penentuan Kinerja

\begin{tabular}{|l|l|l|}
\hline Kinerja & Skor & Nilai \\
\hline$<50 \%$ & -1 & Kurang \\
\hline$\geq 50 \%$ dan $\leq 80 \%$ & 0 & Cukup \\
\hline$>80 \%$ & 1 & Baik \\
\hline
\end{tabular}




\section{HASIL DAN PEMBAHASAN}

\section{Kinerja Perspektif Pelanggan}

a. Kepuasan Pelanggan

Tabel 2

Tingkat Kepuasan Pasien Rawat Jalan Rumah Sakit dr. Etty Asharto Batu Tahun 2018

\begin{tabular}{|l|l|l|}
\hline KETERANGAN & NILAI & HASIL KUISIONER \\
\hline SANGAT TIDAK PUAS (STP) & $760-1.368$ & \\
\hline TIDAK PUAS (TP) & $1.369-1.977$ & \\
\hline CUKUP PUAS (CP) & $1.978-2.586$ & \\
\hline PUAS (P) & $2.587-3.195$ & 2.939 \\
\hline SANGAT PUAS (SP) & $3.196-3.804$ & \\
\hline
\end{tabular}

Sumber: Data Diolah peneliti

Tabel 3

Tingkat Kepuasan Pasien Rawat Inap Rumah Sakit dr. Etty Asharto Batu Tahun 2018

\begin{tabular}{|l|l|l|}
\hline KETERANGAN & NILAI & HASIL KUISIONER \\
\hline SANGAT TIDAK PUAS (STP) & $800-1.440$ & \\
\hline TIDAK PUAS (TP) & $1.441-2.081$ & \\
\hline CUKUP PUAS (CP) & $2.082-2.722$ & \\
\hline PUAS (P) & $2.723-3.363$ & 3.237 \\
\hline SANGAT PUAS (SP) & $3.364-4.004$ & \\
\hline
\end{tabular}

Sumber : Data Diolah Peneliti

Dari tabel 2 dapat dilihat bahwa Indeks kepuasan yang didapat melalui penyebaran kuisioner ialah 2.939 point, maka pelanggan bisa dikategorikan puas atas pelayanan jasa rawat jalan yang sudah diberikan oleh Rumah Sakit dr. Etty Asharto Batu. Pada tabel 3 dapat diketahui bahwa Indeks kepuasan pelanggan rawat inap yang didapat dari penyebaran kuisioner ialah 3237 point, maka pelanggan (pasien) dapat kategori puas atas pelayanan jasa rawat inap yang sudah diberikan oleh Rumah Sakit dr. Etty Asharto Batu. Hal ini sudah sesuai dengan misi Rumah Sakit dr.Etty Asharto Batu yaitu menyediakan sumber daya manusia yang handal dan berempati terhadap pengguna layanan di Rumah Sakit dr.Etty Asharto Batu.

b. Akuisisi Pelanggan

Tabel 4

Akuisisi Pasien Rawat Jalan Rumah Sakit dr. Etty Asharto Batu

\begin{tabular}{|l|l|l|l|}
\hline TAHUN & PASIEN BARU & TOTAL & AKUISISI \\
\hline 2014 & 8.098 & 24.044 & $33,68 \%$ \\
\hline 2015 & 6.552 & 20.345 & $32,20 \%$ \\
\hline 2016 & 7.058 & 22.291 & $31,66 \%$ \\
\hline 2017 & 5.901 & 20.204 & $29,21 \%$ \\
\hline 2018 & 4.362 & 18.307 & $23,83 \%$ \\
\hline
\end{tabular}

Sumber : Data Diolah Peneliti

Pada tabel diatas dapat diketahui bahwa akuisisi pasien rawat jalan Rumah Sakit dr.Etty Asharto Batu terus mengalami penurunan setiap tahunya pada tahun 2014 hingga tahun 2018 yang artinya Rumah Sakit dr.Etty Asharto belum mampu secara maksimal menarik pasien rawat jalan baru agar memilih berobat di Rumah Sakit dr.Etty Asharto Batu. Hal ini, berarti belum sesuai dengan misi Rumah Sakit dr.Etty Asharto Batu yaitu mewujudkan pelayanan kesehatan unggulan yang profesional dan beretika yang berorientasi pada kebutuhan serta kepuasan pengguna layanan Rumah Sakit dr.Etty Asharto Batu. Dengan demikian, akuisisi pelanggan rawat jalan Rumah Sakit dr.Etty Asharto Batu pada tahun 2014-2018 dinilai kurang baik. 
Tabel 5

Akuisisi Pasien Rawat Inap Tahun 2014-2018

\begin{tabular}{|l|l|l|l|}
\hline TAHUN & PASIEN BARU & TOTAL & AKUISISI \\
\hline 2014 & 870 & 1.994 & $43,63 \%$ \\
\hline 2015 & 960 & 1.707 & $56,24 \%$ \\
\hline 2016 & 615 & 1.714 & $35,88 \%$ \\
\hline 2017 & 586 & 1.622 & $36,13 \%$ \\
\hline 2018 & 643 & 1.733 & $37,10 \%$ \\
\hline
\end{tabular}

Sumber : Data Diolah Peneliti

Akuisisi pasien rawat inap Rumah Sakit dr.Etty Asharto Batu pada tahun 2014-2018 yang ada pada tabeel diatas memiliki kecenderungan meningkat, sehingga dapat disimpulkan bahwa Rumah Sakit dr.Etty Asharto sudah mampu menarik pasien rawat inap baru untuk berobat di Rumah Sakit dr.Etty Asharto Batu. Hal ini berarti sudah sesuai dengan misi Rumah Sakit dr.Etty Asharto Batu yaitu mewujudkan pelayanan kesehatan unggulan yang profesional dan beretika yang berorientasi pada kebutuhan serta kepuasan pengguna layanan Rumah Sakit dr.Etty Asharto Batu. Dengan demikian dapat disimpulkan bahwa akuisisi pasien rawat inap Rumah Sakit dr.Etty Asharto Batu dinilai baik.

c. Retensi Pelanggan

Tabel 6

Retensi Pasien Rawat Jalan Tahun 2014-2018

\begin{tabular}{|l|l|l|l|}
\hline TAHUN & PASIEN LAMA & TOTAL & RETENSI \\
\hline 2014 & 15.946 & 24.044 & $66,32 \%$ \\
\hline 2015 & 13.802 & 20.345 & $67,83 \%$ \\
\hline 2016 & 15.233 & 22.291 & $68,33 \%$ \\
\hline 2017 & 14.303 & 20.204 & $70,79 \%$ \\
\hline 2018 & 13.945 & 18.307 & $76,17 \%$ \\
\hline
\end{tabular}

Sumber : Data Diolah Peneliti

Pada tabel diatas diketahui bahwa retensi pasien rawat jalan Rumah Sakit dr.Etty Asharto Batu selama tahun 2014-2018 terus meningkat dari tahun ke tahun, sehingga dapat disimpulkan bahwa Rumah Sakit dr.Etty Asharto Batu selama tahun 2014-2018 sudah mampu untuk mempertahankan pasien lama rawat jalan untuk tetap berobat di Rumah Sakit dr.Etty Asharto Batu. Hal tersebut artinya sudah sesuai dengan misi Rumah Sakit dr.Etty Asharto Batu yaitu mewujudkan pelayanan kesehatan unggulan yang profesional; dan beretika yang berorientasi pada kebutuhan serta kepuasan pengguna layanan Rumah Sakit dr.Etty Asharto Batu. Dengan demikian, dapat disimpulkan bahwa retensi pasien rawat jalan Rumah Sakit dr.Etty Asharto Batu pada tahun 2014-2018 dinilai baik.

Tabel 7

Retensi Rawat Inap Tahun 2014-2018

\begin{tabular}{|l|l|l|l|}
\hline TAHUN & PASIEN LAMA & TOTAL & RETENSI \\
\hline 2014 & 1.154 & 1.994 & $57,87 \%$ \\
\hline 2015 & 747 & 1.707 & $43,76 \%$ \\
\hline 2016 & 1.099 & 1.714 & $64,11 \%$ \\
\hline 2017 & 1.036 & 1.622 & $63,87 \%$ \\
\hline 2018 & 1.090 & 1.733 & $62,89 \%$ \\
\hline
\end{tabular}

Sumber : Data Diolah Peneliti

Berdasarkan tabel 7 dapat diketahui bahwa retensi pasien rawat inap Rumah Sakit dr.Etty Asharto Batu dalam tahun 2014-2018 memiliki kecenderungan menurun, yang artinya Rumah Sakit dr.Etty Asharto belum mampu untuk mempertahankan pelanggan lama rawat inap untuk tetap memilih berobat di Rumah Sakit dr.Etty Asharto. Hal tersebut berarti belum sesuai dengan misi Rumah Sakit dr.Etty Asharto Batu yaitu mewujudkan pelayanan kesehatan unggulan yang profesional dan beretika yan berorientasi pada kebutuhan serta kepuasan pengguna layanan Rumah Sakit dr.Etty Asharto Batu. 
Dngan demikian, retensi pelanggan rawat jalan Rumah Sakit dr.Etty Asharto Batu selama tahun 20142018 dinilai kurang baik.

\section{Kinerja Perspektif Proses Bisnis Internal}

Tabel 8

Hasil Penilaian Kinerja Perspektif Bisnis Internal Rumah Sakit dr. Etty Asharto Batu Tahun 2014-2018

\begin{tabular}{|l|l|l|l|}
\hline KETERANGAN & RATA-RATA 2014-2018 & STANDAR & KRITERIA \\
\hline BOR $(\%)$ & $35,3 \%$ & $60 \%-85 \%$ & KURANG \\
\hline BTO (Kali) & 44 Kali & $40-50$ Kali & BAIK \\
\hline TOI (Hari) & 6 Hari & $1-3$ Hari & KURANG \\
\hline ALOS (Hari) & 3 Hari & $6-9$ Hari & KURANG \\
\hline GDR $(\%)$ & $1,6 \%$ & $\leq 45 \%$ & BAIK \\
\hline NDR $(\%)$ & $0,6 \%$ & $\leq 25 \%$ & BAIK \\
\hline
\end{tabular}

Sumber : Kepala Rumah Sakit dr. Etty Asharto Batu

a. Bed Occupancy Ratio (BOR)

Rata-rata BOR di Rumah Sakit dr.Etty Asharto Batu selama tahun 2014-2018 masih berada di bawah standar yaitu 35,3\% sedangkan Depkes menetapkan standar ideal untuk BOR adalah 6085\%. Artinya Rumah Sakit dr.Etty Asharto Batu masih belum mampu untuk memaksimalkan penggunaan tempat tidur yang ada di Rumah Sakit dr.Etty Asharto Batu dengan baik. Hal ini berarti belum sesuai dengan misi Rumah Sakit dr.Etty Asharto Batu yaitu mewujudkan pelayanan kesehatan unggulan yang profesional dan beretika yang berorientasi pada kebutuhan serta kepuasan pengguna layanan Rumah Sakit dr.Etty Asharto Batu. Dengan demikian, Bed Occupancy Ratio (BOR) dalam tahun 2014-2018 dinilai kurang baik.

b. Bed Turn Over (BTO)

Rata-rata BTO di Rumah Sakit dr.Etty Asharto Batu pada tahun 2014-2018 sudah berada dalam standar yang telah ditetapkan oleh Depkes yaitu 44 kali, sedangkan standar ideal yang sudah ditetapkan oleh Depkes adalah 40-50 kali. Hal ini berarti dari pasien keluar hingga pasien masuk lagi sudah baik sehingga tidak ada pasien yang tidak mendapatkan tempat tidur. Hal ini berarti sudah sesuai dengan misi Rumah Sakit dr.Etty Asharto Batu yaitu mewujudkan pelayanan kesehatan unggulan yang profesional dan beretika yang berorientasi pada kebutuhan serta kepuasan pengguna layanan Rumah Sakit dr.Etty Asharto Batu. Dengan demikian, Bed Turn Over (BTO) dalam tahun 2014-2018 dinilai baik.

c. Turn Over Interval (TOI)

Rata-rata TOI di Rumah Sakit dr.Etty Asharto Batu selama tahun 2014-2018 melebihi dari standar ideal yang sudah ditetapkan Depkes yaitu 6 hari, sedangkan standar ideal yang ditetapkan oleh Depkes adalah 1-3 hari. Artinya hari kosong di Rumah Sakit dr.Etty Asharto Batu terlalu lama, maka cash flow Rumah Sakit dr.Etty Asharto tidak bisa cepat. Hal ini berarti belum sesuai dengan misi Rumah Sakit dr.Etty Asharto Batu yaitu mewujudkan pelayanan kesehatan unggulan yang profesional dan beretika yang berorientasi pada kebutuhan serta kepuasan pengguna layanan Rumah Sakit dr.Etty Asharto Batu. Dengan demikian, Turn Over Interval (TOI) dalam tahun 20142018 dinilai kurang baik.

d. Average Leangth of Stay (ALOS)

Rata-rata ALOS di Rumah Sakit dr.Etty Asharto Batu masih berada dibawah standar idela yang ditetapkan oleh Depkes yaitu 3 hari, sedangkan standar yang ditetapkan oleh Depkes ialah 6 - 9 hari. Terlalu kecilnya nilai ALOS atau dibawah standar akan mengurangi tingkat kenyamanan serta kesembuhan pasien karena pasien belum benar-benar sembuh sudah keluar dari rumah sakit. Hal ini berarti belum sesuai dengan misi Rumah Sakit dr.Etty Asharto Batu yaitu mewujudkan pelayanan kesehatan unggulan yang profesional dan beretika yang berorientasi pada kebutuhan serta kepuasan pengguna layanan Rumah Sakit dr.Etty Asharto Batu. Dengan demikian, Average Leanght of Stay (ALOS) dalam tahun 2014-2018 dinilai kurang baik, maka diberi skor -1. 
e. $\quad$ Gross Death Rate (GDR)

Rata-rata GDR di Rumah Sakit dr.Etty Asharto Batu sudah berada dalam standar idela yang ditetapkan oleh Depkes yaitu 1,6\% sedangkan standar ideal yang ditetapkan oleh Depkes adalah $\leq$ $25 \%$. Artinya bahwa pasien yang meninggal dari 1000 pasien yang keluar tidak sampai melebihi 25 pasien, maka Rumah Sakit dr.Etty Asharto sudah mampu untuk menjaga mutu pelayananya sehingga pasien pulang dengan mendapat kesembuhan. Hal ini berarti sudah sesuai dengan misi Rumah Sakit dr.Etty Asharto Batu yaitu mewujudkan pelayanan kesehatan unggulan yang profesional dan beretika yang berorientasi pada kebutuhan serta kepuasan pengguna layanan Rumah Sakit dr.Etty Asharto Batu. Dengan demikian, Gross Death Rate (GDR) dalam tahun 20142018 dinilai baik.

f. $\quad$ Net Death Rate (NDR)

Rata-rata NDR di Rumah Sakit dr.Etty Asharto Batu sudah berada dalam standar idela yang ditetapkan oleh Depkes, yaitu 0,6\%, sedangkan standar ideal yang ditetapkan oleh Depkes adalah $\leq 45 \%$. Artinya pasien meninggal setelah 2 hari penanganan dari 1000 pasien tidak melebihi 45 pasien, maka Rumah Sakit dr.Etty Asharto sudah mampu untuk menjaga mutu pelayananya sehingga pasien pulang dengan mendapat kesembuhan. Hal ini berarti sudah sesuai dengan misi Rumah Sakit dr.Etty Asharto Batu yaitu mewujudkan pelayanan kesehatan unggulan yang profesional dan beretika yang berorientasi pada kebutuhan serta kepuasan pengguna layanan Rumah Sakit dr.Etty Asharto Batu. Dengan demikian, Net Death Rate (NDR) dalam tahun 2014-2018 dinilai baik.

\section{Kinerja Perspektif Pembelajaran dan Pertumbuhan}

a. Tingkat Kepuasan Karyawan

Tabel 9

Tingkat Kepuasan Karyawan Rumah Sakit dr.Etty Asharto Batu Tahun 2018

\begin{tabular}{|l|l|l|}
\hline KETERANGAN & NILAI & HASIL KUISONER \\
\hline SANGAT TIDAK PUAS(STP) & $1.512-2.721$ & \\
\hline TIDAK PUAS (TP) & $2.722-3.931$ & \\
\hline CUKUP PUAS (CP) & $3.932-5.141$ & \\
\hline PUAS (P) & $5.142-6.351$ & 5.374 \\
\hline SANGAT PUAS (SP) & $6.352-7.561$ & \\
\hline
\end{tabular}

Sumber : Data Diolah Peneliti

Indeks kepuasan yang didapat melalui penyebaran kuisioner ialah 5.374 point, maka pelanggan bisa dikategorikan puas selama bekerja di Rumah Sakit dr. Etty Asharto Batu. Dengan demikian artinya karyawan Rumah Sakit dr.Etty Asharto Batu sudah puas dan nyaman selama bekerja di Rumah Sakit dr.Etty Asharto Batu dikarenakan Rumah Sakit dr.Etty Asharto Batu mampu membuat suasana kerja para karyawan nyaman dan lokasi Rumah Sakit dr.Etty Asharto Batu yang mudah dijangkau bagi karyawan serta pihak Rumah Sakit mampu untuk menjalin hubungan baik dengan warga sekitar. Hal ini sudah sesuai dengan misi Rumah Sakit dr.Etty Asharto Batu yaitu menyediakan sumber daya manusia yang handal dan berempati terhadap pengguna layanan di Rumah Sakit dr.Etty Asharto Batu. 
b. Perputaran Karyawan

Tabel 10

Nilai Perputaran Karyawan Rumah Sakit dr. Etty Asharto Batu Tahun 2014-2018

\begin{tabular}{|l|l|}
\hline TAHUN & HASIL PERPUTARAN KARYAWAN \\
\hline 2014 & $19 \%$ \\
\hline 2015 & $19,83 \%$ \\
\hline 2016 & $14,83 \%$ \\
\hline 2017 & $13 \%$ \\
\hline 2018 & $12 \%$ \\
\hline
\end{tabular}

Sumber : Data Diolah Peneliti

Berdasarkan dari tabel diatas dapat diketahui bahwa perputaran karyawan Rumah Sakit dr.Etty Asharto Batu pada tahun 2014-2018 memiliki kecenderungan menurun, yang artinya Rumah Sakit dr.Etty Asharto Batu mampu untuk menjaga karyawanya dan membuat karyawan nyaman bekerja di Rumah Sakit dr.Etty Asharto Batu sehingga hanya sedikit karyawan yang keluar dari Rumah Sakit dr.Etty Asaharto Batu. Semakin karyawan Rumah Sakit dr.Etty Asharto Batu nyaman bekerja di Rumah Sakit dr.Etty Asharto Batu maka kemungkinan makin lama bekerja di Rumah Sakit dr.Etty Asharto Batu, dengan begitu karyawan akan semakin berpengalaman. Hal ini sudah sesuai dengan misi Rumah Sakit dr.Etty Asharto Batu yaitu menyediakan sumber daya manusia yang handal dan berempati terhadap pengguna layanan di Rumah Sakit dr.Etty Asharto Batu. dengan demikian, kepuasan karyawan di Rumah Sakit Etty Asharto Batu dinilai baik.

c. Produktivitas Karyawan

Tabel 11

Produktivitas Karyawan Rumah Sakit dr.Etty Asharto Batu Tahun 2014-2018

\begin{tabular}{|l|l|l|l|}
\hline TAHUN & $\begin{array}{l}\text { TOTAL } \\
\text { PENDAPATAN }\end{array}$ & $\begin{array}{l}\text { TOTAL } \\
\text { KARYAWAN }\end{array}$ & $\begin{array}{l}\text { PRODUKTIVITAS } \\
\text { KARYAWAN }\end{array}$ \\
\hline 2014 & Rp.8.308.693.925 & 93 & Rp.89.340.794 \\
\hline 2015 & Rp.7.484.963.808 & 90 & Rp.83.166.264 \\
\hline 2016 & Rp.8.262.226.511 & 94 & Rp.87.896.026 \\
\hline 2017 & Rp.7.805.071.244 & 80 & Rp.97.563.390 \\
\hline 2018 & Rp.8.979.180.362 & 98 & Rp.91.624.289 \\
\hline
\end{tabular}

Sumber : Kepala Rumah Sakit dr.Etty Asharto Batu

Dari tabel diatas dapat diketahui bahwa produktivitas karyawan di Rumah Sakit dr.Etty Asharto Batu selama tahun 2014-2018 mengalami peningkatan lebih besar daripada penurunan, yang artinya karyawan Rumah Sakit dr.Etty Asharto Batu sudah memaksimalkan tenaganya untuk mendapatkan pendapatan bagi Rumah Sakit dr.Etty Asharto Batu. Hal ini berarti sudah sesuai dengan misi Rumah Sakit dr.Etty Asharto Batu yaitu menyediakan sumber daya manusia yang handal dan berempati terhadap pengguna layanan di Rumah Sakit dr.Etty Asharto Batu. Dengan demikian dapat disimpulkan bahwa produktivitas karyawan Rumah Sakit dr.Etty Asharto Batu selama tahun 2014-2018 dinilai baik. 
4. Kinerja Perspektif Keuangan

a. Rasio Ekonomis

Tabel 12.

Rasio Ekonomis Rumah Sakit dr.Etty Asharto Batu Tahun 2014-2018

\begin{tabular}{|l|l|l|l|}
\hline TAHUN & TOTAL BELANJA & ANGGARAN & RASIO EKONOMIS \\
\hline 2014 & Rp.6.730.218.359 & Rp.7.113.031.426 & $84,62 \%$ \\
\hline 2015 & Rp.6.516.167.939 & Rp.6.658.031.426 & $97,87 \%$ \\
\hline 2016 & Rp.7.272.884.769 & Rp.8.943.125.271 & $81,32 \%$ \\
\hline 2017 & Rp.6.598.584.091 & Rp.6.747.449.317 & $97,79 \%$ \\
\hline 2018 & Rp.7.166.082.790 & Rp.7.281.372.038 & $98,42 \%$ \\
\hline
\end{tabular}

Sumber : Kepala Rumah Sakit dr.Etty Asharto Batu

Berdasarkan tabel diatas dapat diketahui bahwa rasio ekonomis Rumah Sakit dr.Etty Asharto Batu pada tahun 2014-2018 cenderung mengalami kenaikan tetapi tidak sampai melebihi 100\% ( $<$ < $100 \%$ ). Artinya belanja Rumah Sakit dr.Etty Asharto Batu tidak pernah melebihi dari anggaran yang sudah ditetapkan dan cenderung mengalami kenaikan yang artinya banyak aktivitas yang dilakukan oleh Rumah Sakit dr.Etty Asharto Batu, maka dari itu berarti Rumah Sakit dr.Etty Asharto sudah mampu berhemat dalam belanjanya dan juga mampu untuk melakukan perbaikan jika dilihat dari meningkatnya aktivitas. Hal ini berarti sudah sesuai dengan misi Rumah Sakit dr.Etty Asharto Batu yaitu menyediakan sumber daya manusia yang handal dan berempati terhadap pengguna layanan di Rumah Sakit dr.Etty Asharto Batu. Dengan demikian, dapat disimpulkan bahwa rasio ekonomis Rumah Sakit dr.Etty Asharto Batu pada tahun 2014-2018 dinilai baik.

b. Rasio Efisiensi

Tabel 13

Rasio Efisiensi Rumah Sakit dr.Etty Asharto Batu Tahun 2014-2018

\begin{tabular}{|l|l|l|l|}
\hline TAHUN & TOTAL BELANJA & $\begin{array}{l}\text { REALISASI } \\
\text { PENDAPATAN }\end{array}$ & RASIO EFISIENSI \\
\hline 2014 & Rp.6.730.218.395 & Rp.8.308.693.925 & $81 \%$ \\
\hline 2015 & Rp.6.516.167.939 & Rp.7.484.963.808 & $87 \%$ \\
\hline 2016 & Rp.7.272.884.769 & Rp.8.262.226.511 & $88 \%$ \\
\hline 2017 & Rp.6.598.584.091 & Rp.7.805.071.244 & $84 \%$ \\
\hline 2018 & Rp.7.166.082.790 & Rp.8.979.180.362 & $79 \%$ \\
\hline
\end{tabular}

Sumber : Kepala Rumah Sakit dr.Etty Asharto Batu

Rasio efisiensi Rumah Sakit dr.Etty Asharto Batu selama tahun 2014-2018 berdasarkan dari tabel diatas cenderung mengalami penurunan daripada peningkatan dan tidak sampai melebihi $100 \%$ (x $<100 \%$ ). Artinya belanja Rumah Sakit dr.Etty Asharto Batu tidak pernah melebih pendapatan yang dihasilkan dan juga semakin menurun persentasenya maka semakin bagus karena dapat menunjukkan bahwa selisih antara belanja dan pendapatan semakin besar yang artinya pendapatan semakin besar dan belanja semakin kecil, maka dari itu berarti Rumah Sakit dr.Etty Asharto Batu sudah mampu menyeimbangkan antara belanja rumah sakit dengan pendapatan yang diterimanya. Hal ini berarti sudah sesuai dengan misi Rumah Sakit dr.Etty Asharto Batu yaitu menyediakan sumber daya manusia yang handal dan berempati terhadap pengguna layanan di Rumah Sakit dr.Etty Asharto Batu. Dengan demikian, dapat disimpulkan bahwa rasio ekonomis Rumah Sakit dr.Etty Asharto Batu pada tahun 2014-2018 dinilai baik. 
c. Rasio Efektivitas

Tabel 14

Tabel Rasio Efektivitas Rumah Sakit dr.Etty Asharto Batu Tahun 2014-2018

\begin{tabular}{|l|l|l|l|}
\hline TAHUN & $\begin{array}{l}\text { REALISASI } \\
\text { PENDAPATAN }\end{array}$ & $\begin{array}{l}\text { TARGET } \\
\text { PENDAPATAN }\end{array}$ & RASIO EFEKTIVITAS \\
\hline 2014 & Rp.8.308.693.925 & Rp.8.213.864.236 & $101 \%$ \\
\hline 2015 & Rp.7.484.963.808 & Rp.10.316.176.968 & $72 \%$ \\
\hline 2016 & Rp.8.262.226.511 & Rp.9.431.710.050 & $87 \%$ \\
\hline 2017 & Rp.7.805.071.244 & Rp.7.686.739.224 & $101 \%$ \\
\hline 2018 & Rp.8.979.180.362 & Rp.9.589.427.137 & $93 \%$ \\
\hline
\end{tabular}

Sumber : Kepala Rumah Sakit dr.Etty Asharto Batu

Rasio efektivitas di Rumah Sakit dr.Etty Asharto Batu selama tahun 2014-2018 berdasarkan tabel 19 pada tahun 2014 dan 2017 dapat mencapai lebih dari 100\% yaitu 101\%. Artinya realisasi pendapatan Rumah Sakit dr.Etty Asharto Batu sudah mampu mencapai bahkan melebihi target pendapatan yang sudah ditetapkan. Untuk tahun 2015, 2016, dan 2018 belum mampu mencapai target pendapatan namun hampir mencapai target pendapatan karena tidak jauh dari $100 \%$. Dalam hal ini berarti tindakan yang dilakukan oleh Rumah Sakit dr.Etty Asharto Batu sudah hampir bahkan mampu mencapai target pendapatan yang diinginkan. Hal ini berarti sudah sesuai dengan misi Rumah Sakit dr.Etty Asharto Batu yaitu mewujudkan pelayanan kesehatan unggulan yang profesional dan beretika yang berorientasi pada kebutuhan serta kepuasan pengguna layanan Rumah Sakit dr.Etty Asharto Batu. Dengan demikian dapat disimpulkan bahwa rasio efektivitas Rumah Sakit dr.Etty Asharto Batu selama 2014-2018 dinilai baik.

\section{SIMPULAN DAN SARAN}

Kinerja Rumah Sakit dr.Etty Asharto Batu dilihat dari perspektif pelanggan dengan indikator kepuasan pelanggan melalui kuisioner dapat disimpulkan bahwa pelanggan (pasien) sudah merasa puas atas kinerja Rumah Sakit dr.Etty Asharto Batu. Sementara itu, untuk indikator akuisisi pasien rawat jalan mengalami penurunan setiap tahunya pada tahun 2014-2018, maka dapat disimpulkan bahwa akuisisi pasien rawat jalan dinilai kurang baik. Pada indikator akuisisi pasien rawat inap mengalami kecenderungan meningkat yang dihitung dari tahun 2014-2018. Oleh karena itu, dapat disimpulkan untuk akuisisi pasien rawat inap Rumah Sakit dr.Etty Asharto dinilai baik. Pada indikator retensi pasien rawat jalan mengalami kenaikan setiap tahunya pada tahun 2014-2018. Dengan demikian, dapat disimpulkan retensi pasien rawat jalan Rumah Sakit dr.Etty Asharto dinilai baik. Pada indikator retensi pasien rawat inap mengalami kecenderungan menurun pada periode 2014-2018, maka dapat disimpulkan bahwa retensi pasien rawat inap Rumah Sakit dr.Etty Asharto dinilai kurang baik.

Kinerja Rumah Sakit dr.Etty Asharto Batu dilihat dari perspektif proses bisnis internal dengan indikator Bed Occupancy Rate (BOR) yang di rata-rata dari tahun 2014 hingga tahun 2018 menghasilkan angka di bawah standar, maka dapat disimpulkan BOR di Rumah Sakit dr.Etty Asharto Batu pada tahun 2014-2018 dinilai kurang baik. Pada indikator Bed Turn Over (BTO) Rumah Sakit dr.Etty Asharto Batu yang di rata-rata dari tahun 2014 hingga tahun 2018 menghasilkan angka dalam batas standar, maka dapat disimpulkan bahwa BTO di Rumah Sakit dr.Etty Asharto Batu pada tahun 2014-2018 dinilai baik. Pada indikator Turn Over Internal (TOI) yang di rata-rata dari tahun 2014 hingga tahun 2018 menghasilkan angka di atas standar, maka dapat disimpulkan bahawa TOI di rumah sakit dr.Etty Asharto Batu pada tahun 2014-2018 dinilai kurang baik. Pada indikator Average Leanght of Stay (ALOS) yang di rata-rata dari tahun 2014 hingga tahun 2018 menghasilkan angka yang berada dibawah standar, maka dapat disimpulkan ALOS di Rumah Sakit dr.Etty Asharto Batu pada tahun 20142018 dinilai kurang baik. Pada indikator Net Death Rate (NDR) yang di rata-rata dari tahun 2014 hingga tahun 2018 menghasilkan angka yang masih dalam standar, maka dapat disimpulkan bahwa NDR Rumah Sakit dr.Etty Asharto Batu pada tahun 2014-2018 dinilai baik. Pada indikator Gross Death Rate (GDR) pada Rumah Sakit dr.Etty Asharto Batu yang dirata-rata dari tahun 2014 hingga tahun 2018 menghasilkan angka yang masih dalam 
standar, maka dapat disimpulkan bahwa GDR di Rumah Sakit dr.Etty Asharto Batu dinilai baik.

Kinerja Rumah Sakit dr.Etty Asharto Batu dinilai dari perspektif pembelajaran dan pertumbuhan untuk indikator kepuasan karyawan melalui kuisioner kepuasan karyawan yang disebarkan kepada 72 karyawan dapat disimpulkan karyawan puas selama bekerja di Rumah Sakit dr.Etty Asharto Batu. Pada indikator perputaran karyawan Rumah Sakit dr.Etty Asharto Batu selama tahun 2014-2018 mengalami kecenderungan menurun, maka dapat disimpulkan bahwa perputaran karyawan Rumah Sakit dr.Etty Asharto Batu pada tahun 2014-2018 dinilai baik. Pada indikator produktivitas karyawan di Rumah Sakit dr.Etty Asharto Batu pada tahun 2014-2018 mengalami peningkatan lebih besar daripada penurunan yaitu peningkatan, maka dapat disimpulkan bahwa produktivitas karyawan Rumah Sakit dr.Etty Asharto Batu pada tahun 2014-2018 dinilai baik.

Kinerja Rumah Sakit dr.Etty Asharto Batu dinilai dengan perspektif keuangan pada rasio ekonomis cenderung mengalami kenaikan daripada penurunan dan berada dibawah $100 \%$ ( $<<100 \%$ ), maka dapat disimpulkan rasio ekonomis Rumah Sakit dr.Etty Asharto Batu pada tahun 2014-2018 dinilai baik. Pada rasio efisiensi Rumah Sakit dr.Etty Asharto Batu mengalami peningkatan lebih kecil dibanding penurunan dan berada di abwah 100\% ( $x<100 \%)$. Oleh karena itu, dapat disimpulkan bahwa rasio efisiensi di Rumah Sakit dr.Etty Asharto Batu pada tahun 2014-2018 dinilai baik. Pada rasio efektivitas Rumah Sakit dr.Etty Asharto Batu mengalami peningkatan yang lebih kecil dibanding penurunan serta pada tahun 2014 dan 2017 mampu merealisasikan pendapatan lebih dibanding targetnya. Dengan demikian, dapat disimpulkan bahwa rasio efektivitas Rumah Sakit dr.Etty Asharto Batu pada tahun 2014-2018 dinilai kurang baik.

Pihak Rumah Sakit dr.Etty Asharto Batu sebaiknya menerapkan penilaian kinerja dengan menggunakan metode Balanced Scorecard untuk kedepannya. Pihak Rumah Sakit Etty Asharto Batu untuk kedepanya sebaiknya lebih memperhatikan bagaimana caranya untuk menarik pasien baru (pasien rawat jalan) agar memilih pasien pasien baru memilih untuk berobat di Rumah Sakit dr.Etty Asharto Batu. Pihak Rumah Sakit dr.Etty Asharto Batu sebaiknya memperhatikan mengenai bagaimana mempertahankan pasien lama (pasien rawat inap) agar pasien lama untuk kedepannya tetap percaya kepada Rumah Sakit dr.Etty Asharto Batu untuk berobat lagi.

Pihak Rumah Sakit dr.Etty Asharto sebaiknya memperhatikan mengenai pemanfaatan tempat tidur digunakan dalam satu periode dan memperhatikan mengenai berapa lama tempat tidur kosong dalam satu periode.

\section{DAFTAR PUSTAKA}

Darini, Tuningrat, I Ketut Satriawan. 2015. Analisa Kinerja Perusahaan Dengan Menggunakan Metode Balanced Scorecard (Studi Kasus PT. X Cabang Tabanan). Jurnal Rekayasa dan Manajemen Agroindustri, Volume 3, No 4.

Laksmita dan Januarti. 2011. Analisis Pengukuran Kinerja Perusahaan Dengan Metode Balanced Scorecard (Studi Kasus di PT. Bank Jateng Cabang Utama Semarang). Skripsi. Universitas Diponegoro. Semarang.

Parmita. 2015. Analisis Pengukuran Kinerja Rumah Sakit Dengan Pendekatan Balanced Scorecard Pada Rumah Sakit Daerah Madani Palu. e-Jurnal Katalogis, No. 5.

Rusdiyanto. 2010. Analisis Kinerja Dengan Pendekatan Balanced Scorecard Pada PDAM Kabupaten Semarang. Skripsi. Universitas Diponegoro. Semarang.

Pramadhany. 2011. Penerapan Metode Balanced Scorecard Sebagai Tolok Ukur Penilaian Kinerja Pada Organisasi Nirlaba (Studi Kasus Pada Rumah Sakit Bhayangkara Semarang). Skripsi. Universitas Diponegoro. Semarang.

Darmiyati. 2013. Penerapan Balanced Scorecard Sebagai Metode Pengukuran Kinerja Pada RS IPHI Pedan Kabupaten Klaten. Skripsi. Universitas Diponegoro. Semarang.

Khasanah. 2016. Evaluasi Kinerja Di Rumah Sakit Islam Yogyakarta PDHI (Tinjauan Balanced Scorecard). Skripsi. Universitas Islam Negeri Sunan Kalijaga. Yogyakarta.

Pamungkas. 2014. Pengukuran Kinerja Dengan Elemen-Elemen Balanced Scorecard (Studi Empiris RSUD Sukoharjo). Skripsi. Universitas Muhammadiyah Surakarta. 
Sari. 2017. Kinerja Karyawan Pada Rumah Sakit Umum Pusat Haji Adam Malik Medan. Skripsi. Universitas Medan Area. Medan.

Departemen Kesehatan Republik Indonesia. 2005. Direktorat Bina Pelayanan Medik. Jakarta.

Widodo. 2011. Analisis Kinerja Perusahaan dengan Menggunakan Pendekatan Balanced Scorecard (Studi Kasus pada Perusahaan Mebel PT.Jansesn Indonesia). Skripsi. Universitas Diponegoro. Semarang.

Aurora. 2010. Penerapan Balanced Scorecard Sebagai Tolak Ukur Pengukuran Kinerja (Studi Kasus Pada RSUD Tugurejo Semarang). Skripsi. Universitas Diponegoro. Semarang.

Undang-undang Pasal 3. Tentang Tujuan Penyelengaraan Rumah Sakit.

Mentri Kesehatan RI No.983/Menkes/per/II 1992 Tentang Tugas Rumah Sakit.

Undang-undang No. 44 Tahun 2009 Tentang Fungsi Rumah Sakit.

Peraturan Menteri Kesehatan Republik Indonesia N0.340/Menkes/Per/III/2010 Tentang Klasifikasi Rumah Sakit.

Hanuma. 2010. Analisis Balanced Scorecard Sebagai Alat Pengukur Kinerja Perusahaan (Studi Kasus Pada PT. Astra Honda Motor). Skripsi. Universitas Diponegoro. Semarang.

Lestari. 2016. Pengukuran Kinerja Dengan Pendekatan Balanced Scorecard Pada Rumah Sakit PKU Muhammadiyah Gombong Tahun 2013 Dan 2014. Skripsi. Universitas Negeri Yogyakarta.

Pramusinta. 2016. Implementasi Balanced Scorecard Sebagai Tolok Ukur Kinerja Rumah Sakit Ibu Dan Anak Puri Bunda Malang. Skripsi. Universitas Merdeka Malang.

Febriyanti. 2016. Analisis Kinerja Rumah Sakit Dengan Pendekatan Balanced Scorecard Studi Kasus di RSUD Wonosari. Skripsi. Universitas Sanata Dharma. Yogyakarta. 